\title{
LA VALUACION JUDICIAL DE LOS DAÑOS Y PERJUICIOS
}

I

\section{CONCEPTOS GENERALES SOBRE LA INDEMNIZACION DE DAÑOS Y PERJUICIOS}

"Si el deudor no cumple su obligación cuando y como debiera, el acreedor tiene el derecho de obtener una indemnización por daños y perjuicios; es decir, una suma en dinero equivalente al provecho que hubiera obtenido del cumplimiento efectivo y exacto de la obligación, a título de indemnización por el perjuicio sufrido" (1).

Indemnizar quiere decir poner a una persona, en cuanto sea posible, en la misma situación en que se encontraria si no se hubiese producido el acontecimiento que obliga a la indemnización. La indemnización de daños y perjuicios está destinada a restablecer el estado de las cosas que se habian tenido en mira al concertar el contrato. La indemnización, en este orden de ideas, llena una función de equivalencia destinada a equilibrar los intereses económicos en juego.

Para que proceda la indemnización de daños y perjuicios se requiere la concurrencia de tres elementos:

a) La inejecución de la obligación, que es el elemento objetivo

b) La imputabilidad del deudor, o sea el vínculo de causalidad entre el dolo y la culpa y el daño, que es el elemento subjetivo; $y$

c) El daño, pues la responsabilidad del deudor no queda comprometida sino cuando la inejecución de la obligación ha causado daño al acreedor.

1 Planiol, Marcelo y Ripert, Jorge, Tratado Práctico de Derecho Civil Francés, Tomo VII, Las Obligaciones (Segunda parte), № 821, p. 132.

\section{A) La inejecución de la obligación}

El primer elemento, la inejecución de la obligación, no requiere mayores comentarios.

El deudor, simplemente, incumple la obligación, o la cumple en forma parcial o defectuosa, sea por acción o por omisión.

Corresponde al juez, en cada caso, apreciar la inejecución de la obligación o su cumplimiento parcial o defectuoso. Toca al acreedor, sin embargo, demostrar la existencia de la obligación, tratándose de las obligaciones de dar y de hacer, y en el caso de las obligaciones de no hacer probar además el incumplimiento. En la misma medida en que toca al deudor, en las obligaciones de dar y de hacer, demostrar el cumplimiento. Así lo exige el artículo 1282 del Código Civil, y es por ello que el deudor puede retener el pago mientras no le sea otorgado el recibo correspondiente (2).

\section{B) La imputabilidad del deudor}

Para que el daño sea imputable se requiere un nexo causal entre la acción u omisión del deudor, que obedezca a dolo o a culpa (3), y la inejecución de la obligación. Sólo interesa, para los efectos indemnizatorios, aquel daño que constituye una consecuencia del hecho o de la omisión que obliga a reparar.

Advertimos que ha merecido escaso interés la elaboración de una teoría orgánica del nexo entre el hecho o

2 Artículo 1243 del Código Civil.

3 Existe dolo cuando el deudor tiene conciencia de no cumplir su obligación, sea con el propósito de causar daño al acreedor o no.

Cuando el deudor, por negligencia, omite ejecutar la prestación prometida, en el caso de las obligaciones de dar o de hacer, o abstenerse, en el caso de las obligaciones de no hacer, incurre en culpa. 
la omisión por dolo o por culpa del deudor y el daño que origina y que da lugar a la indemnización.

Ello obedece, por cierto, a que se trata de un problema muy complejo que puede superar todos los cálculos o previsiones. La difícil cuestión del nexo causal no puede recogerse en formas abstractas. El juez, en caso de duda, deberá apreciar todas las circunstancias, y su poder para hacerlo es soberano.

La situación de imputabilidad del deudor está vinculada, en realidad, a múltiples factores. Porque así como el dolo o la culpa determinan responsabilidad, el caso fortuito o fuerza mayor exoneran de ella. Porque el deudor en mora es responsable de los daños y perjuicios que ocasiona el retardo, mientras que el deudor no constituido en mora no incurre en responsabilidad. Porque el deudor exonerado, por pacto de responsabilidad, no está obligado a indemnizar los daños y perjuicios resultantes del incumplimiento, salvo que éste provenga del dolo o de la culpa inexcusable (4), mientras que en ausencia de este convenio sí lo está. Sólo cabe observar que la prueba de la exoneración de responsabilidad corresponde al deudor. La inejecución de la obligación hace que se presuma, en la legislación peruana, la culpa del deudor (5).

\section{C) El daño}

El daño es todo detrimento que sufre una persona por la inejecución de la obligación. El daño, para que sea reparado, debe ser cierto. No eventual o hipotético.

Daño es sinónimo de perjuicio. Así lo establecen la mayoría de las legislaciones modernas y el Código Civil peruano (6).

Ambas palabras, sin embargo, tuvieron en su origen un significado distinto. El daño de la ley Aquilia era el ataque a la integridad de una cosa $y$, aunque no hubiera perjuicio, estaba sancionado.

El Código Civil mejicano distingue, como regla excepcional en relación con las otras legislaciones, los conceptos de daño y de perjuicio. Aunque sus acepciones son distintas a las del derecho romano. El artículo 2108 del Código Civil mejicano establece que "se entiende por daño la pérdida o menoscabo sufrido en el patrimonio por la falta de cumplimiento de una obligación"; y el artículo 2109 del mismo código prescribe que: "se reputa perjuicio la privación de cualquier ganancia lí-

4 Artículo 1321 del Código civil.

5 Artículo 1326 del Código civil.

6 Artículos 1319, 1320, 1323 y 1324 del Código civil. cita que debiera haberse obtenido con el cumplimiento de la obligación". La distinción mejicana corresponde a los conceptos de daño emergente y de lucro cesante.

Para que haya un daño contractual resarcible no basta que se incumpla la obligación y que el incumplimiento sea imputable al deudor. Es necesario, además, que el incumplimiento produzca un perjuicio.

Toda reclamación de daños y perjuicios, aunque se funde en un derecho inobjetable a exigirlos, requiere la prueba de su existencia. Para declarar la responsabilidad no basta comprobar judicialmente la infracción de la obligación; es preciso demostrar la existencia de los daños y perjuicios. Por ello, el incumplimiento de un contrato no origina necesariamente el derecho a una reparación. Tiene que haber daño. La responsabilidad civil, a diferencia de la responsabilidad penal, no es punitiva.

Así, si el deudor incumple su obligación por dolo o por culpa y el acreedor no sufre daño alguno, entonces no hay lugar a la indemnización; por ejemplo, cuando el mandatario no adquiere las acciones que le encomendó comprar su mandante y éstas bajan de valor en el mercado, siendo posible obtenerlas por un precio inferior. En este caso, ¿qué se indemnizaría?

El principio general admite, sin embargo, excepciones. Las más frecuentes se presentan en las obligaciones con cláusula penal y en las obligaciones de dar sumas de dinero.

Cuando se ha estipulado la obligación con cláusula penal, el acreedor, al menor teóricamente, no tiene que probar el monto de los daños y perjuicios que le ha irrogado el incumplimiento.

Pero en la legislación peruana generalmente debe hacerlo, por la norma imperativa del artículo 1227 del Código Civil. Esta regla exige al juez reducir equitativamente la pena cuando es manifiestamente excesiva, y ello obliga a que usualmente ambas partes, tanto el acreedor como el deudor, se pronuncien sobre el monto de los daños y perjuicios. El primero, el acreedor, tratando de demostrar su existencia y su cuantia para evitar que sea reducida la cláusula penal. El segundo, el deudor, tratando de probar su inexistencia para obtener la reducción. $Y$ es lógico que así sea; si no, ¿cómo podría el juez, prima facie, decidir que la pena es manifiestamente excesiva, desconociendo los daños y perjuicios que causa la inejecución?

Anotamos, sin embargo, que en estos casos el juez está obligado a reducir equitativamente la pena, pero que no está ni obligado ni facultado para suprimirla. 
La indemnización pactada por la cláusula penal, aunque en algunos casos pueda convertirse en simbólica, siempre subsiste.

En las obligaciones de dar sumas de dinero sucede algo similar respecto a la prueba de los daños y perjuicios.

Cuando no existe pacto entre las paries, la demora en entregar una suma de dinero se repara con el interés legal. Aquí el acreedor no tiene que probar la existencia o el monto de los daños y perjuicios. Igual solución prevalece cuando las partes han estipulado un interés convencional, dentro de los límiles autorizados por el legislador, para los mismos casos de demora en la entrega de una suma de dinero. Aqui el acreedor tampoco tendrá que probar la existencia o cuantía de los daños y perjuicios.

Hemos dicho que la indemnización, para ser completa, debe comprender todo lo nacesario a fin de colocar al acreedor en la misma situacićn jurídica en que se encontraria si la obligación hubiese sido cumplida. Por eso, el acreedor tiene el derecho de exigir las pérdidas sufridas y las utilidades frustradas.

Las pérdidas que sufre el acreedor como consecuencia de la inejecucićn de la obligación corresponden al daño emergente y las utilidades que deja de percibir, con motivo de la misma inejecución, corresponden al lucro cesante. El daño emergente es el empobrecimiento del patrimonio del acreedor. El lucro cesante corresponde al legitimo enriquecimiento que se frustró.

La doctrina (7) cita con frecuencia el caso de "un contrato celebrado entre un empresario de conciertos y un artista de fama, para dar un concierto en una fecha determinada: si el artista no cumple lo convenido, la obligación de pagar daños e intereses comprenderá los dos elementos siguientes: 1). los gastos hechos por el empresario, por ejemplo: gastos de publicación y anuncio del concierto, alquiler y arreglo del local, etc., todos los cuales implican una disminución de su patrimonio $y$, por consiguiente, pérdidas sufridas por él (damnum emergens); 2). las utilidades que hubiera podido obtener por la venta de localidades (lucrum cessans)".

7 Josserand, Luis, Derecho Civil, Tomo II, Volumen I, Teotía General de las Obligaciones, 1950, No 626, p. 507; Salvat, Raymundo M., Tratado de Derecho Civil Argentino, Obligaciones en General, I, (1952), No 81, p. 95; Alessandri Rodríguez, Arturo y Somarriva Undurraga, Manuel, Curso de Derecho Civil, Tomo III, De las Obligaciones, (1941), No 359, p. 216.
La prueba del daño emergente es relativamente senciIla. La prueba del lucro cesante es más compleja. EI lucro cesante generalmente no puede acreditarse enforma directa. Entonces, cuando la ganancia podia esperarse con probabilidad, debe suponerse que esa ganancia se hubiera hecho, ya que todo hombre común suele hacerla. Por eso el lucro cesante es aquello que según las circunstancias pudiera haberse esperado con probabilidad.

Los daños y perjuicios revisten dos formas. Compensatorios y moratorios. En rigor ambos, los daños y perjuicios moratorios y los daños y perjuicios compensatorios, son compensatorios, pues los primeros, simplemente, están destinados a resarcir el retraso que se produce en el cumplimiento de la obligación. Pero, por comodidad de expresión, se utilizan ambas palabras.

Los daños y perjuicios compensatorios son los que se acuerdan al acreedor por la inejecución de las obligación. Se trata de una ejecución por equivalente; los daños y perjuicios entran en lugar de la prestación prometida y compensan la falta de cumplimiento.

Los daños y perjuicios moratorios son los que el deudor está obligado a abonar al acreedor por el retraso en el cumplimiento de la obligación. Después de algún retardo el deudor ejecuta su obligación; pero debe indemnizar al acreedor por este retardo.

Los daños y perjuicios compensatorios y moratorios se rigen por las mismas reglas. Sin embargo, para que el acreedor exija daños y perjuicios moratorios es siempre necesario que el deudor sea constituido en mora, salvo las excepciones previstas por la ley (8); mientras que para exigir daños y perjuicios compensatorios no siempre es necesaria la constitución en mora del deudor y generalmente los determina el juez, soberanamente, en razón de los perjuicios sufridos por el acreedor.

Por ejemplo, para exigir daños y perjuicios moratorios en las obligaciones de dar sumas de dinero, es necesario, salvo que la ley, el pacto o la naturaleza y circunstancias de la obligación indiquen lo contrario, que el deudor sea constituido en mora.

Para exigir el pago de daños y perjuicios compensatorios no siempre se requiere la constitución en mora del deudor. Así, si el deudor se obliga a no actuar en un teatro y lo hace, la obligación ya habría sido infringida y el acreedor, simplemente, tendria el derecho de exigir el pago de daños y perjuicios compensatorios.

8 Artículo 1254 del Código civil. 
Advertimos, por último, que los daños y perjuicios moratorios se exigen siempre conjuntamente con la ejecución directa, en especie, de la prestación, mientras que los daños y perjuicios compensatorios son incompatibles con la ejecución en especie, pues importarían un doble pago.

| 1

\section{VALUACION DE LOS DAÑOS Y PERJUICIOS}

\section{Formas de determinarlos}

Los daños y perjuicios por la inejecución de las obligaciones contractuales se determinan en tres formas: judicial, convencional y legalmente.

La valuación judicial, como su nombre lo indica, es la que efectúa el juez. Es la más frecuente. Ella opera cuando los contratantes no han estipulado la indemnización para el caso de incumplimiento, y cuando ésta tampoco ha sido fijada por la ley.

La valuación convencional (9) es la que determinan las propias partes, en la época de contraer la obligación o después, pero antes del incumplimiento; los contratantes, mediante la llamada cláusula penal, valorizan anticipadamente los daños y perjuicios para el caso de inejecución.

Se llama valuación legal a la indemnización fijada por el legislador para ciertas obligaciones, en particular las de dar sumas de dinero. En estos casos la indemnización de daños y perjuicios por el incumplimiento de la obligación no es señalada ni por el juez ni por las partes, sino por la ley. Su aplicación más frecuente se presenta en las obligaciones de dar sumas de dinero.

En las obligaciones de esta clase la indemnización, salvo pacto en contrario, está constituida por el interés legal; la reparación, en estos casos, se fija de antemano por la ley. $\mathrm{Ni}$ el acreedor tiene que demostrar la cuantía de los perjuicios sufridos por el retraso en el cumplimiento de dar una suma de dinero, ni el deudor, por su parte tiene derecho de pretender exonerarse de tal pago, aduciendo que el incumplimiento no ha originado perjuicios al acreedor.

Se trata de una presunción que no admite prueba en contrario. La ley presume siempre el daño y lo presume para todos. Este criterio tiene sólidos fundamentos. El

9 Ver Inmutabilidad de la Cláusula Penal, del mismo autor, publicado en la revista "Derecho", XXIV, 1965, páginas $11 \mathrm{y}$ siguientes. uso general del dinero, su potencialidad como medio general de cambio y la inversión que el acreedor proyectaba efectuar, originarían graves dificultades y controversias interminables si se tratara de demostrar el monto de las ganancias frustradas por el incumplimiento. El daño sufrido por el acreedor originaría largos debates, muy difíciles, por cierto, de resolver.

\section{Diferencias y similitudes entre las tres formas de valua- ción de los daños y perjuicios}

Las valuaciones judicial, convencional y legal tienen similitudes y diferencias que podemos sintetizar como sigue:

1. Las indemnizaciones judicial y legal siempre están constituidas por una suma de dinero.

La indemnización convencional, fijada por las partes, usualmente consiste en una suma de dinero, pero nada se opone a que esté constituida por cualquier otra obligación de dar, o por una obligación de hacer o de no hacer.

2. En la indemnización judicial el acreedor deberá probar la cuantía de los daños y perjuicios que reclama. En las indemnizaciones convencional y legal, no.

Advertimos, sin embargo, que en la legislación peruana la regla no es absoluta tratándose de las obligaciones con cláusula penal, salvo cuando se pactan intereses convencionales dentro de los límites señalados por el legislador. Como hemos visto, el artículo 1227 del Código Civil exige al juez reducir equitativamente la pena cuando es manifiestamente excesiva. Esto obliga al acreedor, en la mayoría de los casos, a probar el monto de los daños y perjuicios que le irroga el incumplimiento de la obligación. Tratándose de los intereses convencionales, y siempre que se encuentren dentro de los márgenes establecidos por la ley, el juez no podrá modificarlos $y$, por tanto, el acreedor quedará relevado de probar la existencia y la cuantía de los daños y perjuicios que le ha causado la inejecución.

3. La valuación judicial se verifica sólo después de incumplida la obligación, a diferencia de la valuación convencional que es contemporánea con la obligación principal, o, en todo caso, posterior a ella, pero anterior al incumplimiento.

La valuación legal tiene un régimen distinto: ella es fijada por la ley $y$, por tanto, no concurren ni la voluntad de las partes ni la facultad discrecional del juez. 
4. Las indemnizaciones judicial y convencional pueden reparar los daños y perjuicios compensatorios y moratorios, o uno solo de ellos, según se trate de la inejecución absoluta de la obligación o de un retraso.

La indemnización legal, aplicada al caso más frecuente de las obligaciones de dar sumas de dinero, sólo repara los daños y perjuicios moratorios. La ejecución en especie en las obligaciones de dar sumas de dinero, siempre, al menos teóricamente, es posible.

5. Cuando la obligación es indivisible $y$ hay inejecución, las indemnizaciones judicial y legal sólo exigen a los codeudores que hubiesen estado dispuestos a cumplir, a contribuir con una cantidad correlativa a la porción del precio de la cosa o del servicio (artículo 1207 de Código Civil).

No sucede lo mismo en las obligaciones con cláusula penal, cuando esta prestación es indivisible. En estos casos cada uno de los codeudores y de sus herederos quedan obligados a satisfacer la pena entera (artículo 1229 del Código Civil).

6. Cuando la obligación es solidaria y se incumple, las indemnizaciones judicial y legal sólo exigen a los codeudores solidarios pagar el valor de la prestación, pero por los daños y perjuicios únicamente responde el culpable (artículo 1220 del Código Civil).

Si la obligación consignada en la cláusula penal es solidaria, cada codeudor responde por el integro de esta indemnización convencional y no sólo por el valor de la prestación principal incumplida (artículo 1220 y 1229 del Código Civil).

\section{III}

\section{VALUACION JUDICIAL DE LOS DAÑOS $Y$ PERJUICIOS}

\section{Problemas que suscita}

Emitido el concepto de la valuación judicial de los daños y perjuicios y establecidas las similitudes y diferencias más saltantes con la valuación convencional y con la valuación legal, restan estudiar los tres problemas fundamentales que, en nuestra opinión, suscita la valuación judicial de la indemnizacićn por la inejecución de las obligaciones contractuales. Entendemos que ellos son los siguientes:

1. ¿Debe aplicarse el mismo criterio para determinar los daños y perjuicios por inejecución de la obligación por dolo y por culpa del deudor, o deben ser apreciados con mayor severidad en el primer caso?
2. Dentro del sistema del Código Civil peruano, ¿qué son los daños previstos o que se pudieron prever? ¿Qué son los daños imprevistos? ¿Cuáles son las consecuencias directas e indirectas? ¿Cuáles las inmediatas, mediatas y acausales?

3. Los conceptos de previsión e imprevisión, ¿se refieren a la naturaleza de los daños y perjuicios o a su cuantía?

Trataremos estos tres problemas en el orden propuesto.

\section{Responsabilidad por inejecución de las obligaciones contractuales por culpa y por dolo del deudor.}

El Código Civil peruano, siguiendo las doctrinas de Dumoulin, Domat y Pothier y las normas del Código Civil francés, establece responsabilidades diferentes por la inejecución de la obligación por culpa y por dolo del deudor. En el primer caso hace al deudor responsable de los daños y perjuicios "previstos o lo que se hubiese podido prever al tiempo de constituirse la obligación y que sean consecuencia necesaria de su falta de cumplimiento" (artículo 1323 del Código Civil). En el segundo, "de todos los que conocidamente se deriven de la falta de cumplimiento de la obligación, como efecto directo e inmediato" (artículo 1323 del Código Civil).

Se distingue, pues, entre los daños y perjuicios previstos o que se pudieron prever, para el caso de culpa, y los daños y perjuicios imprevistos, para el caso de dolo. En ambas hipótesis se exige, sin embargo, el vínculo directo de causa a efecto entre el incumplimiento y el daño, usándose la palabra "necesaria", para la culpa, y la expresión "directo e inmediato", para el dolo.

No es éste, sin embargo, el criterio uniforme de la legislación y de la doctrina.

Algunos autores sostienen que en el derecho romano el deudor era responsable de todos los daños y perjuicios, directos o indirectos. Parece, sin embargo, que en el derecho romano ya existía responsabilidad distinta por culpa y por dolo del deudor, cuando se trataba del incumplimiento de las obligaciones contractuales. En el caso de culpa el deudor sólo respondía de los daños y perjuicios previstos; en el caso de dolo, también de los imprevistos.

Escriche (10), comentando la antigua legislación española, admite que no habia preceptos claros, como

1. Diccionario Razonado de Legislación y Jurisprudencia, tomo II, (1874), p. 601 . 
los del derecho moderno, pero que, en todo caso, tratárase de dolo o de culpa del deudor, éste sólo respondía de los daños y perjuicios previstos o que podian haberse previsto al concertar el contrato y siempre que fueran consecuencia directa e inmediata de la inejecución de la obligación. Se descartaban, en ambos casos, los daños y perjuicios imprevistos y los indirectos, mediatos y casuales.

Fue Dumoulin el primero en poner orden en la doctrina, interpretando los textos romanos. Domat $y$, particularmente, Pothier, consagran el principio.

Según Pothier (11), cuando el deudor incumplia la obligación por culpa sólo era responsable por los daños y perjuicios previstos, los mismos que, en principio, se circunscribían a la cosa objeto de la obligación. Cuando la obligación se incumplía por dolo, el deudor también respondía de los daños y perjuicios imprevistos, los mismos que, en principio, no estaban limitados a los que sufría el deudor en el bien objeto de la obligación, sino también a los que alcanzaban a sus otros bienes.

Pero en ambos casos Pothier exigía que los daños y perjuicios fueran consecuencia necesaria de la falta de cumplimiento de la obligación, y no consecuencia lejana o remota.

La doctrina de Pothier, con ciertas modificaciones, inspiró al Código Napoleón y ejerció influencia decisiva en casi todas las legislaciones del siglo pasado y de este siglo (Código Civil italiano de 1865, artículos 1228 y 1229; Código Civil italiano de 1942, artículos 1223 y 1225; Código Civil uruguayo, artículo 1320; Código Civil boliviano, artículos 743 y 744 ; Código Civil chileno, artículo 1558; Código Civil colombiano, artículo 1616; Código Civil mejicano, artículo 2110; Código Civil venezolano, artículos 1274 y 1275; y Código Civil argentino, artículos 520 y 521 ).

El sistema del Código Civil alemán de 1900 (artículos 249 y 252) y el Código federal suizo de las obligaciones (artículos 42, 43 y 99) es, sin embargo, distinto. Ellos consagran la doctrina de la responsabilidad total, el principio de "la reparación integral del daño", sin distinguir entre el dolo y la culpa, entre el daño directo y el daño indirecto, entre las consecuencias previstas y las consecuencias imprevistas.

Entonces, la disyuntiva surge por si sola. Cuál sistema es más conveniente, ¿el francés, seguido por la ma-

11 Tratado de las Obligaciones, Nos. 159 y siguientes, Págs. 13.3 y siguientes. yoría de las legislaciones, entre otras por el Código Civil peruano? ¿O el alemán, seguido por el Código federal suizo de las obligaciones?

El primer sistema, el francés, toma en consideración la mayor o menor imputabilidad del deudor para fijar el monto de los daños y perjuicios: en caso de culpa, el deudor sólo responde de los daños y perjuicios previstos o que pudieron preverse; en caso de dolo, también de los imprevistos. Pero en ambos casos se limita la responsabilidad del deudor a los daños y perjuicios que sean consecuencia "necesaria" o "directa e inmediata" de la inejecución. Se excluyen, pues, los daños y perjuicios que son consecuencia circunstancial, indirecta o mediata del incumplimiento.

El segundo sistema, el alemán, considera, para fijar los daños y perjuicios, el importe total del daño, prescindiendo de la mayor o menor imputabilidad del deudor; y, al hacerlo, ordena la reparación integral, ordena "restablecer el estado de cosas que hubiera existido si la circunstancia que obliga a la indemnización no hubiese sobrevenido" (artículo 249, 1, del Código Civil alemán).

Advertimos que el artículo 1107 del Código Civil español (12) acepta, según Sánchez Román, una posición intermedia. Dice Sánchez Román (13), refiriéndose a los daños y perjuicios, que "si proceden de dolo se deberán todos los que conocidamente se deriven del incumplimiento de la obligación, entendiéndose por daños conocidos los que tal concepto merezcan al prudente arbitrio del juez, aunque no sean su consecuencia directa, inmediata e inevitable"; $y$, refiriéndose al caso de culpa, agrega que "se deberán sólo aquellos perjuicios que, producto del incumplimiento del contrato, sean, además, consecuencia directa, inmediata e inevitable $y$, por consiguiente, se han previsto o podido prever, al tiempo de celebrarse; pero no todos los demás que sobrevinieren al contratante perjudicado, aunque tengan relación más o menos próxima con dicho incumplimiento".

Sin embargo, esta opinión de Sánchez Román no es compartida por Calixto Valverde y Valverde (14) quien,

12 "Los daños y perjuicios de que responde el deudor de buena fe son los previstos o que se hayan podido prever al tiempo de constituirse la obligación, y que sean consecuencia necesaria de su falta de cumplimiento. En caso de dolo responderá el deudor de todos los que conocidamente se deriven de la falta de cumplimiento de la obligación".

13 Sánchez Román, Felipe, Estudios de Derecho Civil, Derecho de Obligaciones, tomo IV, (1899), N? 38, p. 321.

14 Tratado de Derecho Civil Español, 1920, p. 114. 
comentando el mismo artículo 1107 del Código Civil español, señala que el deudor, en caso de dolo, responde de los daños previstos y de los imprevistos; y en caso de culpa sólo de los previstos o previsibles; pero que en ambos casos los daños tienen que ser consecuencia necesaria, directa e inmediata de la falta de cumplimiento. Según Valverde y Valverde, aunque el artículo 1107 del Código Civil español no coincide en las palabras con sus modelos, los códigos francés e italiano, reproduce su espíritu.

En estos términos se plantea el debatido problema de la extensión de la responsabilidad por la inejecución de las obligaciones contractuales.

Los defensores de la tesis objetiva, de la tesis de la "reparación integral" consagrada por el Código Civil alemán, aducen que la reparación tiene por objeto colocar al acreedor en las condiciones más similares a las que se encontraria de haber sido oportunamente cumplida la obligación; que el perjuicio que ocasiona el deudor al incumplir su obligación no se modifica por el hecho que tal incumplimiento obedezca a dolo o a culpa; que la inejecución por culpa puede producir consecuencias más graves para el acreedor que la inejecución por dolo; y que medir el daño por el estado anímico del deudor es propio del Derecho penal, mas no del Derecho Civil, que es un derecho de intereses y no de intenciones, de indemnizaciones y no de penas.

Esta tesis ha sido defendida con calor, en el Perú, por el doctor Lizardo Alzamora Silva (15).

Se pregunta el doctor Alzamora Silva, ¿qué es lo previsible? ¿Qué es lo que no se pudo prever? ¿Cuál es la línea que separa lo que es consecuencia mediata de lo que es consecuencia inmediata? $Y$ añade que no es admisible que, por el hecho de aceptarse en el dolo un factor de imputabilidad que no existe en la culpa, ésta sea tratada con menos rigor que aquélla, pues la imputabilidad concurre en ambos casos.

Para el doctor Alzamora Silva existen, pues, objeciones doctrinarias -el elemento de la imputabilidad- y objeciones prácticas, de hecho -la dificultad de apreciar lo previsto y lo imprevisto, lo mediato y lo inmediato, lo directo y lo indirecto, lo necesario y lo circunstancial- que se oponen a la distinción entre la responsabilidad por dolo y por culpa del deudor.

Más pesan en nuestro ánimo, sin embargo, los fundamentos de la doctrina francesa, que es la misma que con-

15 El Dolo en nuestra Legislación Civil, (1926), págs. 205 y siguientes. sagra el artículo 1323 del Código Civil, aceptada por distinguidos tratadistas, entre otros por Colin y Capitant (16), Planiol y Ripert (17), Chironi (18), León Barandiarán (19), Salvat (20), Colmo (21), Giorgi (22) y Bibiloni (23).

Cuando el deudor incumple su obligación por culpa es, sin lugar a dudas, negligente, pero procede con buena fe; su descuido revela falta de diligencia, pero no inmoralidad. En el dolo hay intención de incumplir la obligación, bien para causar un daño al deudor, bien para obtener un provecho económico superior violando el contrato. En el dolo el deudor procede con mala fe; el dolo no sólo revela falta de diligencia, sino también inmoralidad.

No podia, pues, tratarse de igual manera al deudor de buena fe $y$ al deudor de mala fe. En el primer caso no se debía atribuir responsabilidad sino por los daños previstos o que pudieron preverse; no se debía ir más lejos. En el segundo caso la ley tenía que ser más severa; el deudor debía responder aun de los daños y perjuicios imprevistos.

Cuando el deudor incurre en culpa sería injusto hacerlo responsable de lo que no podía prever, precisamente por el menor grado de imputabilidad. La noción de imputabilidad no puede ser descartada en esta materia. Ella es, precisamente, el elemento esencial sobre el que se basa el resarcimiento, pues éste se excluye cuando el deudor no es imputable.

La teoría del Código impide abrumar al deudor con una serie de consecuencias imprevistas e ilimitadas; evita agobiarlo con cargas inesperadas. En caso contrario el deudor negligente podría llegar a ser responsable por

16 Colin, Ambrosio y Capitant, H., Curso Elemental de Derecho Civil, tomo III, Tema General de las Obligaciones, (1924), págs. 43 y 44.

17 Obra cit., Nos. 858 y siguientes, págs. 170 y siguientes.

18 Chironi, G. P., La Culpa en el Derecho Civil Moderno, (1907), Nos. 253 y siguientes, págs. 637 y siguientes.

19 León Barandiarán, José, Comentarios al Código Civil Peruano, Obligaciones, Tomo II, Modalidades y Efectos, (1956), Págs. 605 y siguientes.

$20 \mathrm{Ob}$. Cit., Nos. 166 y siguientes, págs. 192 y siguientes.

21 Colmo, Alfredo, De las Obligaciones en General, Tomo I, (1928), Nos. 131 y siguientes, páginas 105 y siguientes.

22 Giorgi, Jorge, Teoría de las Obligaciones en el Derecho Moderno, Vol. II, (1909), Nos. 97 y siguientes, págs. $141 \mathrm{y}$ siguientes.

23 Bibiloni, Juan Antonio, Anteproyecto de Reformas al Código Civil Argentino, Obligaciones, (1929), págs. 57 y siguientes. 
la muerte del acreedor que, ante la bancarrota, opta por suicidarse.

$Y$ aclaremos que para hacer el distingo entre la responsabilidad contractual por dolo y por culpa no tenemos necesidad de recurrir a la interpretación de Planiol y Ripert (24), forzada por cierto, de entender que el aumento de la indemnización por dolo obedece a una responsabilidad extracontractual o delictuosa, que, prolongando la responsabilidad contractual, produciría la reparación íntegra del daño; pues la responsabilidad, en todo caso, trátese de culpa o de dolo, tiene su fundamento en el contrato.

Creemos, en conclusión, con von lhering (25), que "el que a sabiendas e intencionalmente ha causado daño a tercero, no puede sustraerse a una reparación completa; ha sabido y querido lo que ha hecho. La medida de la falta determina la de la responsabilidad: el dolus obliga de manera absoluta a todos los daños e intereses; la culpa no obliga sino dentro de ciertos límites".

\section{Alcances del artículo 1323 del Código Civil peruano.}

El segundo problema que suscita la valuación judicial de los daños y perjuicios es la interpretación del artículo 1323 del Código Civil, cuando se refiere, en caso de inejecución por culpa del deudor, a "los daños y perjuicios previstos, o los que se hubiese podido prever al tiempo de constituirse la obligación y que sean consecuencia necesaria de su falta de cumplimiento", y, en caso de inejecución por dolo, a "todos los que conocidamente se deriven de la falta de cumplimiento de la obligación, como efecto directo e inmediato".

¿Cuáles son los alcances de la norma? Tratemos, en primer lugar, de no perdernos en juegos de palabras. La regla del Código, y lo mismo sucede en la mayoría de las legislaciones, es muy elaborada, hasta reiterativa, pero su sentido es claro. La norma abstracta debía limitarse a señalar, como lo ha hecho, simples pautas o criterios directivos de carácter general, que el juez, utilizando en cada caso las enseñanzas de la doctrina y su propia experiencia, aplica.

Por eso los romanos y Pothier enseñaban la doctrina de los daños y perjuicios previstos o imprevistos, necesarios o circunstanciales, directos 0 indirectos, mediatos o inmediatos, con ejemplos, evitando incurrir en lucubraciones de oscuro significado jurídico.

24 Ob. cit., $N^{\circ} 865$, p . 177.

25 Ihering, R. von, Etudes Complementaires: De la Faute en Droit Privé, p. 63.
Cuando se trata de los daños y perjuicios previstos, los alcances del precepto son muy simples: él se refiere a aquellos que, según se desprende del conirato, las partes tuvieron en cuenta al contraer la obligación.

Las dificultades se presentan al tratarse de determinar cuáles son los daños y perjuicios que se pudieron prever y cuáles los que no se pudieron prever. ¿Cómo podría recogerse un criterio preciso acerca de los daños y perjuicios imprevistos en una norma abstracta?

$Y$ lo mismo sucede con los daños y perjuicios inmediatos y mediatos, directos $e$ indirectos, necesarios $y$ circunstanciales.

En algunos casos será posible, sin vacilación, determinar los daños y perjuicios que sufre el deudor: cuando ellos, obviamente, son consecuencia inmediata, directa y necesaria del incumplimiento. Pero esto recién se puede lograr apreciando las consecuencias del incumplimiento en una obligación determinada. $Y$ en este orden de ideas, ¿podría acogerse la distincićn en una fórmula legislativa?

Esto explica que Giorgi (26), citando a Paulo, se preguntará ¿Por qué el vendedor moroso en la entrega del grano vendido no está obligado a pagar al comprador el precio de los esclavos muertos de hambre? $Y$ respondiera diciendo que era racional presumir que el comprador podía haber evitado la pérdida de los esclavos si se hubiera cuidado de buscar en otro sitio el grano que debía entregarse por el vendedor. Y que el mismo Giorgi, citando a Ulpiano, se preguniara ¿.por qué, al contrario, se pone a cargo del locador que arrendó unos pastos sabiendo que nacian yerbas venenosas, la muerte de las bestias? $Y$ expresara que la presunción natural inducía a considerar que el propietario de las bestias no podía impedir la muerte.

$Y$ es por ello también que Pothier (27) ilustraba la distinción con los ejemplos clásicos de la venta de ganado, considerando daños y perjuicios previstos a aquellos que el acreedor sufria en el bien objeto de la obligación, e imprevistos a aquellos que el acreedor sufria en sus otros bienes.

Así, si el deudor no entregaba el caballo objeto de la obligación de dar, en tiempo oportuno, por culpa, era responsable por el mayor precio que debia pagar el acreedor por otro caballo. Pero si a causa de la demora el acreedor no cobraba cierta suma de dinero en el lugar donde debía haberse trasladado con el caballo objeto de la obligación, el deudor respondia de este per-

26 Ob. cit., No 99, p. 149.

27 Ob. cit., Nos. 161 y siguientes, págs. 134 y siguientes. 
juicio. El primero era directo; el segundo indirecto. Excepcionalmente -agregaba Pothier- el deudor respondia de este último perjuicio cuando él había sido previsto al con'raerse la obligación.

Si el deudor entregaba al acreedor, dolosamente, una vaca infectada, respondia no sólo por el daño en la vaca misma, sino por $e l$ resto del ganado que sufria el contagio. Pero el deudor no era responsable de las consecuencias lejanas y circunstanciales de la inejecución dolosa; por ejemplo, si como consecuencia del contagio el acreedor no habia podido cultivar las tierras y había quebrado.

$Y$ si es cierto que Pothier sentó las bases que prevalecen en el derecho moderno acerca de la distinción entre los daños y perjuicios previstos e imprevistos y directos e indirectos, también es cierto que la mayoría de las legislaciones, entre ellas el Código Civil peruano, han descartado la antigua distincićn entre los daños intrínsecos, o sea aquellos de los que es responsable el deudor culpable y que se circunscriben al bien objeto de la obligación, y los daños extrinsecos, o sea aquellos de los que es responsable el deudor doloso y que alcanzan a otros bienes del acreedor.

Porque parece indudable, de acuerdo con la regla consignada en el artículo 1323 del Código Civil, que el deudor culpable también respondería, en el ejemplo de Pothier, de los daños y perjuicios originados por el contagio en el resto del ganado del acreedor. Se trataría de daños y perjuicios que podian haber sido previstos y de daños y perjuicios ocasionados como consecuencia necesaria de la inejecución.

Hemos visto que el artículo 1323 del Código Civil peruano distingue, en primer lugar, entre los daños y perjuicios previstos o que se hubiesen podido prever y los imprevistos.

También hemos expresado que los daños y perjuicios previstos son los que las partes, al contraer la obligación, tuvieron en cuenta que produciría el incumplimiento.

La apreciación de los daños y perjuicios que se pudieron prever o que no se pudieron prever depende de la naturaleza de la obligación $y$, en definitiva, del criterio soberano del juez. Una observacićn sí es necesario formular. Lo previsible o imprevisible no puede considerarse en sentido absoluto sino relativo. En sentido absoluto todo hecho sería previsible $y$, por tanto, el deudor culpable tendría responsabilidad por todos los acontecimientos derivados de la inejecución de la obligación. En sentido relativo, lo previsible es aquello que las partes, razonablemente, pudieron y debieron tener en cuenta, al tiempo de contratar; lo previsible es un factor que se aprecia considerando la naturaleza y circunstancias de la obligacićn.

Hasta aquí lo referente a los daños y perjuicios previstos o que se pudieron prever y a los daños y perjuicios imprevistos.

Pero el Código Civil peruano, al determinar la responsabilidad del deudor culpable, limiténdola a los daños y perjuicios previstos o que se hubieran podido prever al tiempo de constituirse la obligación, exige que ellos sean "consecuencia necesaria de su falta de cumplimiento". ¿Cómo interprełar esła expresión?

Algunos autores, invocando la doctrina de Pothier, señalan que el legislador se ha referido a los daños intrínsecos, excluyendo los extrínsecos. El deudor, en este orden de ideas, sólo sería responsable de los daños y perjuicios que sufriera el acreedor en el bien objeto es la obligación, pero no en sus demás bienes.

Otros autores señalan que el Código, al usar esta terminología, ha querido referirse a los daños y perjuicios que indefectiblemente, de acuerdo con el curso ordinario y normal de la cosas, debe producirse el incumplimiento.

En nuestra opinión, lo único que se propuso el legis. lador fue señalar el vínculo de causa a efecto entre la inejecución y el daño: la consecuencia necesaria sería la determinada por el incumplimiento del deudor, excluyéndose, por cierto, los daños ulteriores que se derivan de nuevas causas, o sea las consecuencias no necesarias o de mera ocasión y, por supuesto, las procedentes de hechos del acreedor. La nueva causa, que excluye la responsabilidad, surgiria cuando para llegar desde el incumplimiento hasta los daños aparecieran eventos extraños, no vinculados necesariamente a la inejecución.

$Y$ significado similar atribuimos a la expresión "efecto directo e inmediato", que usa el Cćdigo con relación al deudor doloso. También, en este caso, se trata de mantener el vínculo de causalidad, excluyéndose del resarcimiento todos aquellos daños que se deriven del incumplimiento por el concurso de nuevas causas. Esta expresión reviste singular importancia cuando se refiere a los daños y perjuicios imprevistos, pues tenía que limitarse, por razones evidentes, la sucesión de acontecimientos causales.

Así, si el deudor se compromete a entregar un cargamento de mercaderías e inejecuta su obligación por culpa, responde del mayor precio de esas mercaderías. 
Estos son los daños y perjuicios previstos o que pudieron preverse al concertarse la obligación; y son, además, consecuencia necesaria de la falta de cumplimiento.

Si la inejecución es por dolo, el deudor también responde por el mayor valor de las mercaderias en el país del extranjero donde proyectaba exportarlas el acreedor, siempre y cuando éste demuestre, en forma indubitable, la verosimilitud de la operación. Si el deudor no tuvo conocimiento de este hecho, y no se trataba de una mercadería que usualmente se exportaba al extranjero, mal podía prever los daños y perjuicios que originaba su incumplimiento. Pero resulta responsable porque se trata de un efecto directo e inmediato.

Pero en ningún caso, haya culpa o dolo del deudor, es éste responsable si el acreedor que vio incumplido su contrato se proveyó de otras mercaderías, infectadas, produciendo una intoxicación masiva en el público; - si adquirió otras mercaderías en buen estado, pero perecieron por naufragio del vapor en que el acreedor las embarcó. Estos daños y perjuicios no serían consecuencia necesaria, directa o inmediata, del insumplimieno del deudor.

\section{Los conceptos de previsión e imprevisión, ¿se refieren a la causa de los daños y perjuicios o a su cuantía?}

Según Giorgi (28), unánimemente se había considerado que el artículo 1150 del Código Napolećn ordenaba que el deudor de buena fe sólo reparaba los daños y perjuicios previstos o previsibles, entendiéndose por tales los previstos o previsibles en cuanto a su monto. Agrega Giorgi que ni en Dumoulin ni en Pothier aparecen vestigios de la doctrina que se refiere a los daños y perjuicios previstos o previsibles en cuanto a su naturaleza o causa.

Colin y Capitant (29) y Planiol y Ripert (30), por el contrario, plantean el problema como una cuestión clásica: la de saber si el deudor debía haber previsto o podido prever únicamente la naturaleza o causa del daño - también su cantidad, o sea la cifra a que alcanza la indemnización al acreedor. $Y$ añaden que si bien Justiniano y la nueva orientación de la legislación francesa se refieren a la cuantía de los daños y perjuicios previstos o que pudieron preverse, las antiguas sentencias se limitaban a exigir tan sólo la previsión de la causa del daño y no la de su cantidad.

28 Ob. Cit., N? 123, p. 175.

29 Ob. Cit., p. 42.

30 Ob. cit., No 864 , pág. 175 y siguientes.
No parece, pues, tan original, como Giorgi la hace ver, la posición asumida por Demolombe, seguido por Laurent y por Chironi, en el sentido de que las expresiones "previstos" o "podido prever" se refieren a la causa del daño y no a la cantidad del daño.

La mayoría de los autores aceptan que el texto legislativo alude al monto del daño y no a su naturaleza o causa; que la palabra daño se refiere al resarcimiento debido y convertido en una suma de dinero; que el deudor de buena fe sólo debe indemnizar con la suma a que pudo prever que ascendían los daños y perjuicios, pues proceder de otra manera seria entrar en el terreno de la imprevisibilidad; y que la fórmula de la previsión, en suma, debe entenderse que regula la cuestión de la cuantía de la indemnización.

Pero Demolombe, con Laurent y Chironi, sostienen que esas expresiones se refieren a la naturaleza o causa del daño y no a su cantidad, y que el deudor que no cumple debe la reparación completa de los daños y perjuicios ocasionados por su culpa, si la causa de los daños fue prevista o pudo preverse, aunque la suma debida estuviese fuera de las previsiones de los contratantes. Y Chironi (31) agrega que "la letra de la disposición y los trabajos preparatorios demuestran que la expresión daños significa los acontecimientos dañosos (causas), previstos o que se podian prever, sin atender a la cantidad a que pueden elevarse. . ".

En nuestra opinión, en ambas tesis hay una parte de verdad; porque consideramos que la expresión "daños previstos o previsibles" comprende tanto la causa del daño como su cuantía.

Creemos que el deudor que incurre en culpa no está obligado por el daño imprevisible en su naturaleza o causa. Porque lo contrario significaría admitir que el deudor culpable también responde de los daños y perjuicios imprevistos. Si al contraerse la obligación no podía suponerse la naturaleza del daño, el acreedor no puede pedir la reparación: el daño sería imprevisto.

El deudor que incurre en culpa tampoco está obligado por el daño imprevisible en su cuantia. El deudor podía prever la naturaleza del daño pero no su monto. La cuantía del daño seria pues imprevisible y, por tanto, el deudor no respondería de ella. Aceptar lo contrario también significaría responsabilizar al deudor culpable por los daños imprevistos.

En suma, en la responsabilidad por culpa se excluye todo lo imprevisible, trátese de la causa o naturaleza del daño, trátese de su cuantía.

31 Ob. cit. N?. 257, p. 650. 